\title{
Pet/Ct Characteristics for Metastasis in Patients Non-Small Cell Lung Cancer
}

\author{
Tran Hoang Vi ${ }^{1}$, Le Minh Quang ${ }^{2}$, Dang Vinh Hiep ${ }^{3}$, Tran Phu Tri ${ }^{4 *}$, Le Cong Tri ${ }^{5}$ and Vo Thi Minh \\ Tri $^{6}$ \\ ${ }^{1}$ Quangngai hospital, Vietnam \\ ${ }^{2}$ Choray hospital, Vietnam
}

${ }^{3}$ Pham Ngoc Thach university of medicine, Vietnam

${ }^{4}$ Danang hospital, Vietnam

${ }^{5}$ Choray hospital, Vietnam

${ }^{6}$ Danang hospital, Vietnam

*Corresponding author: Tran Phu Tri, Danang hospital, Vietnam

\section{ARTICLE INFO}

Received: 慧 July 01, 2020

Published: 幽 July 15, 2020

Citation: Tran Hoang Vi, Le Minh Quang, Dang Vinh Hiep, Tran Phu Tri, Le Cong Tri, Vo Thi Minh Tri. Pet/Ct Characteristics for Metastasis in Patients Non-Small Cell Lung Cancer. Biomed J Sci \& Tech Res 28(5)2020. BJSTR. MS.ID.004719.
ABSTRACT

Objective: To explore the location of lymph nodal and distant organ metastasis; and SUVmax on PET/CT in non-small cell lung cancer.

Subjects and methods: Patients dignosed with non small cell lung cancer based on pathology results were retrospective analyzed at Oncology and Nuclear Medicine Department - Bach Mai Hospital, from November 2015 to October 2018. They were underwent 18F-FDG PET-CT scans before the treatment. The variables include: location, SUVmax of lymph nodal and distant organ metastasis.

Results: PET/CT detects the metastasis at various organs, including mediastinal nodal metastasis, umbilical lymph nodes accounting for the highest rate, respectively $69.5 \%$ and $39.3 \%$; followed by lung metastasis of $37.4 \%$, bone metastasis $32.7 \%$, Supraclavicular lymph nodes $20.8 \%$, abdominal lymph nodes $12.9 \%$, adrenal gland 8.8\%; liver $6.6 \%$, brain $3.1 \%$. SUVmax was highest in liver and abdominal lymph nodes, respectively $7.53 \pm 4.63$ and $7.50 \pm 3.15$; the lowest in lung metastases and lung umbilical lymph nodes, respectively $4.41 \pm 2.81$ and $5.57 \pm 2.46$.

Conclusion: PET/CT is a very good imaging technique for detecting lymph nodal and distant organ metastasis in NSLC.

\section{Introduction}

Lung cancer is a fairly common malignancy of the respiratory system, the most common cause of cancer death in Europe in 2006 (about 334,800 deaths), after prostate cancer and is the most common type of cancer in men. The morbidity and mortality rates in 2006 were 75.3 and 64.8 / 100,000 people / year [1]. According to the statistics of the American Cancer Society in 2006, lung cancer was the leading cause of death in cancers (about 162,460 in 2006), accounting for about $13 \%$ of all cancers and $28 \%$ of the Cancer deaths [2].In Vietnam, according to cancer epidemiological records in 2004, lung cancer is the most common cancer nationwide, ranking first among men with the incidence rate in Hanoi of 39.8 / 100,000 [3].

Lung cancer if detected late, the prognosis is very bad, the mortality rate is very high and death within a short time after the disease is detected. Early diagnosis and evaluation of the stage of lung cancer is a necessary and urgent need. Including important 
help of the diagnostic means. Conventional X-rays and computer tomography are two techniques for casualty survey. However, assessing the stage of the tumor is still limited. In recent years, the role of PET / CT in diagnosing and assessing the stage of non-small cell lung cancer has been increasingly confirmed. However, in our country, there is no research to mention the role of PET / CT in assessing stage of non-small cell lung cancer

\section{Materials and Methods}

Selected as non-small cell lung cancer patients determined by pathological anatomy. Have PET / CT scans according to the method selected in the study. Place: performed at the Department of Oncology and Nuclear Medicine - Bach Mai Hospital. Study period: 11 / 2015-10 / 2018

Study Design: description, retrospective. Convenient sampling: we selected 318 patients eligible for inclusion in the study

\section{Research Facilities and Techniques:}

a) Machine type: PET / CT Biograph True Point - Siemens Germany.

b) F-18 FDG radioactive drugs: F-18 FDG solution (2-fluoro2-deoxy-D-glucose). Dosage 0.15-0.20 mCi / Kg weight (712mCi), intravenous. PET / CT scan: done after F-18 FDG injection 45-60 minutes. Body scan from skull base to $1 / 3$ on femoral bone. Capture additional areas of interest or late as needed.

c) Assess the results to determine the variables: location, size, SUVmax metastases (lung metastases, mediastinal lymph nodes, distal metastases ...)

Results: (Table 1-5)

Table 1: Divide metastasis rate by location.

\begin{tabular}{|c|c|c|}
\hline Metastatic location & Number of cases & Rate \% \\
\hline Brain & 10 & 3,1 \\
\hline Lymph nodes & 36 & 11,3 \\
\hline Submandibular node & 7 & 2,2 \\
\hline Thyroid gland & 2 & 0,6 \\
\hline Supraclavicular lymph nodes & 66 & 20,8 \\
\hline Lung & 119 & 37,4 \\
\hline Pleural & 26 & 8,2 \\
\hline Pericardium & 1 & 0,3 \\
\hline Mediastinal nodal metastasis & 221 & 69,5 \\
\hline Lung umbilical lymph nodes & 127 & 39,3 \\
\hline Axillary lymph node & 16 & 5,0 \\
\hline Esophagus & 3 & 0,9 \\
\hline Liver & 21 & 6,6 \\
\hline Stomach & 3 & 0,9 \\
\hline Abdominal lymph nodes & 41 & 12,9 \\
\hline
\end{tabular}

\begin{tabular}{|c|c|c|}
\hline Adrenal gland & 28 & 8,8 \\
\hline Inguinal lymph node & 3 & 0,9 \\
\hline Bone & 104 & 32,7 \\
\hline Tissue & 12 & 3,8 \\
\hline
\end{tabular}

Note: non-small cell lung cancer metastases to many organ sites, in which metastatic lymph nodes and umbilical lymph nodes accounted for the highest proportion, respectively $69.5 \%$ and $39.3 \%$; followed by lung metastases $37.4 \%$, bone metastases $32.7 \%$, supraclavicular lymph nodes $20.8 \%$, abdominal lymph nodes $12.9 \%$, adrenal metastases $8.8 \%$; liver $6.6 \%$, brain $3.1 \%$.

Table 2: Characteristics of PET / CT in assessment of mediastinal lymph node location.

\begin{tabular}{|c|c|c|}
\hline $\begin{array}{l}\text { Mediastinal lymph node } \\
\text { location }\end{array}$ & $\begin{array}{l}\text { Number of lymph } \\
\text { nodes }(n=281)\end{array}$ & Rate \% \\
\hline Near carina & 3 & 1,1 \\
\hline Under carina & 55 & 19,6 \\
\hline After carina & 2 & 0,7 \\
\hline Above the carina & 10 & 3,6 \\
\hline Before carina & 47 & 16,7 \\
\hline Near the aortic artery & 17 & 6,0 \\
\hline Belowthe aortic artery & 31 & 11,0 \\
\hline Abovethe aortic artery & 1 & 0,4 \\
\hline Before the aortic artery & 5 & 1,8 \\
\hline Near the trachea & 14 & 5,0 \\
\hline Before trachea & 12 & 4,3 \\
\hline Original bronchus & 14 & 5,0 \\
\hline Near the original bronchus & 7 & 2,5 \\
\hline Near the heart & 1 & 0,4 \\
\hline Middle mediastinum & 1 & 0,4 \\
\hline Above mediastinum & 19 & 6,8 \\
\hline Previous mediastinum & 4 & 1,4 \\
\hline Upper mediastinum & 38 & 13,5 \\
\hline
\end{tabular}

Note: Metastatic mediastinal lymph nodes many locations, in which mediastinal lymph nodes under carina and before carina accounted for the highest proportion, respectively $19.6 \%$ and $16.7 \%$.

Table 3: Division of median lymph node diameter.

\begin{tabular}{|c|c|c|}
\hline $\begin{array}{c}\text { Median size of lymph nodes } \\
\text { (cm) }\end{array}$ & $\begin{array}{c}\text { Number of lymph } \\
\text { nodes (n=281) }\end{array}$ & Rate \% \\
\hline$\leq 1$ & 54 & 19,2 \\
\hline$>1-2$ & 144 & 51,2 \\
\hline$>2-3$ & 48 & 17,1 \\
\hline$>3-4$ & 22 & 7,8 \\
\hline$>4-5$ & 4 & 1,4 \\
\hline$>5$ & 9 & 3,2 \\
\hline Smallest, largest, medium & $\begin{array}{c}\text { Minimum: } 0.4 \text { cm; The largest: } 8.2 \mathrm{~cm} \\
\text { Average: } 1.88 \pm 1.19 \mathrm{~cm}\end{array}$ \\
\hline
\end{tabular}

Note: Half of the mediastinal lymph nodes size $>1-2 \mathrm{~cm}$; smallest lymph nodes $0.4 \mathrm{~cm}$ the largest: $8.2 \mathrm{~cm}$; Average: $1.88 \pm 1.19 \mathrm{~cm}$. 
Table 4: Bone metastases location detected on PET / CT.

\begin{tabular}{|c|c|c|}
\hline Location of bone metastases & Number of cases & Rate $\%$ \\
\hline ( $\mathrm{n}=107)$ & Rate $\%$ & 3,1 \\
\hline Spinal metastases & 24 & 22,4 \\
\hline Pelvic metastases & 25 & 23,4 \\
\hline Metastasis of ribs & 21 & 19,6 \\
\hline Multifocal bone metastases & 37 & 34,6 \\
\hline
\end{tabular}

Note: Metastatic bone metastases accounted for a high proportion (34.6\%), pelvic metastases accounted for $23.4 \%$; spine $22.4 \%$ and ribs $19.6 \%$

Table 5: SUVmax of common metastatic lesions.

\begin{tabular}{|c|c|}
\hline Metastatic location & $\begin{array}{c}\text { Number of cases } \\
\text { SUVmax }\end{array}$ \\
\hline (TB \pm SD) & 36 \\
\hline Mediastinal lymph nodes & $6,10 \pm 3,31$ \\
\hline Lung umbilicus lymph node & $5,57 \pm 2,46$ \\
\hline Lung & $4,41 \pm 2,81$ \\
\hline Bone & $6,53 \pm 3,30$ \\
\hline Supraclavicular lymph nodes & $6,05 \pm 2,92$ \\
\hline Abdominal lymph nodes & $7,50 \pm 3,15$ \\
\hline Adrenal gland & $5,83 \pm 3,70$ \\
\hline Liver & $7,53 \pm 4,63$ \\
\hline
\end{tabular}

Note: SUVmaxis highest in liver and abdominal lymph node injury, respectively $7.53 \pm 4.63$ and $7.50 \pm 3.15$; lowest in metastatic lung lesions and umbilical lymph nodes, respectively $4.41 \pm 2.81$ and $5.57 \pm 2.46$.

\section{Discussion}

Non-small cell lung cancer is a malignant disease, with the majority of patients presenting with distant metastases at diagnosis [4]. Research results: UPC metastases to many organ locations, including metastases of mediastinal lymph nodes, umbilical lymph nodes accounted for the highest proportion, respectively $69.5 \%$ and $39.3 \%$; followed by lung metastases $37.4 \%$, bone metastases $32.7 \%$, supraclavicular lymph nodes $20.8 \%$, abdominal lymph nodes $12.9 \%$, adrenal metastases $8.8 \%$; liver $6.6 \%$, brain $3.1 \%$. Metastasis of mediastinal lymph nodes with many positions, in which mediastinal lymph nodes under carina and before carina accounted for the highest proportion, respectively $19.6 \%$ and $16.7 \%$. Half of the mediastinal lymph nodes size $>1-2 \mathrm{~cm}$; smallest lymph nodes $0.4 \mathrm{~cm}$ the largest: $8.2 \mathrm{~cm}$; Average: $1.88 \pm 1.19 \mathrm{~cm}$

Of the 119 cases of lung metastases, $71.4 \%$ of them had lung cancer on the same side, $16.8 \%$ had metastases on the other side and $11.8 \%$ had metastases on both sides.Multifocal bone metastases accounted for a high proportion (34.6\%), pelvic metastases $23.4 \%$; spine $22.4 \%$ and ribs $19.6 \%$.SUVmax is highest in liver and abdominal lymph node lesions, respectively $7.53 \pm 4.63$ and $7.50 \pm 3.15$; lowest in metastatic lung lesions and umbilical lymph nodes, respectively $4.41 \pm 2.81$ and $5.57 \pm 2.46$.The clinical signs and symptoms of lung cancer are often vague or nonspecific, including cough, chest pain, hoarseness, recurrent pneumonia and coughing up blood. Conventional X-rays help find lung nodules or tumors, but often produce false-negative results, especially in earlystage disease [5]. In a study of 396 lung radiographs of proven lung cancer patients from 1992-1995, nearly $20 \%$ of lung cancer was undetectable, usually with nodules less than $1.6 \mathrm{~cm}$ in diameter [6]. Many cases were not detected on radiographs, until lesions were detected relatively large in size [5]. Computed tomography is greatly improved compared to pulmonary X-ray in detecting small lesions [7].

For non-small cell lung cancer, PET / CT is better than computerized tomography for distinguishing benign and malignant lesions and is far more valuable in evaluating lymph node invasion and metastases far from muscles Other officials [8].Research by Antoch et al. [9] shows that the superior detection of PET / CT scans compared with PET scans or computed tomography in evaluating T-stage small cell non-small cell lung cancer (accuracy $94 \%$ with PET / CT versus 75\% of PET or computerized tomography, stage N (93\% accuracy with PET / CT and 63\% for computerized tomography and $89 \%$ for PET alone). PET / CT is also better at detecting distant metastases than CT or PET alone.Although the accuracy of PET / CT is higher than that of computerized tomography in lung cancer assessment. However, in some non-malignant cases such as inflammation, granulomatosis (mycobacterial infection, sarcoidosis), recent surgery may have a false positive result with FDG uptake [10].

\section{Conclusion}

Most cases of non-small cell lung cancer have regional metastases (lung metastases, umbilical lymph nodes, mediastinal lymph nodes) and distant metastases when diagnosed. PET / CT is a very good imaging technique for detecting metastatic lesions, helping to guide treatment and prognosis.

\section{References}

1. Sorensen M, M Pijls Johannesma, E Felip, ESMO Guidelines Working Group (2010) Small cell lung cancer: ESMO Clinical Practice Guidelines for diagnosis, treatment and follow-up. Ann Oncol 21 Suppl 5: v120125.

2. (2006) Cancer Facts and Figures.

3. Nguyen Ba Đuc (2006) The situation of cancer in Vietnam 2001-2004 period. Journal of Practical Medicine 9-17.

4. Demedts I K, K Y Vermaelen J P van Meerbeeck (2010) Treatment of extensive-stage small cell lung carcinoma: current status and future prospects. Eur Respir J 35(1): 202-215.

5. Lobrano M B (2006) Partnerships in oncology and radiology: the role of radiology in the detection, staging, and follow-up of lung cancer. Oncologist 11(7): 774-779.

6. Quekel LG, AG Kessels, R Goei, J M van Engelshoven (1999) Miss rate of lung cancer on the chest radiograph in clinical practice. Chest 115(3): 720-724. 
7. Sone S, F Li, Z G Yang, S Takashima, Y Maruyama, et al. (2000) Characteristics of small lung cancers invisible on conventional chest radiography and detected by population based screening using spiral CT. Br J Radiol 73(866): 137-145.

8. Schrevens L, Natalie Lorent, Christophe Dooms, Johan Vansteenkiste (2004) The role of PET scan in diagnosis, staging, and management of non-small cell lung cancer. Oncologist 9(6): 633-643.

ISSN: $2574-1241$

DOI: 10.26717/BJSTR.2020.28.004719

Tran Phu Tri. Biomed J Sci \& Tech Res

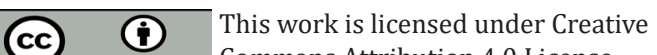

Submission Link: https://biomedres.us/submit-manuscript.php
9. Antoch G, Jörg Stattaus, Andre T Nemat, Simone Marnitz, Thomas Beyer, et al. (2003) Non-small cell lung cancer: dual-modality PET/CT in preoperative staging. Radiology 229(2): 526-533.

10. Kavanagh P V, Aaron W Stevenson, Michael Y Chen, Paige B Clark (2004) Nonneoplastic diseases in the chest showing increased activity on FDG PET. AJR Am J Roentgenol 183(4): 1133-1141.

$\begin{array}{ll}\text { BIOMEDICAL } & \text { Assets of Publishing with us } \\ \text { RESEARCHES } & \text { - Global archiving of articles } \\ \text { - Immediate, unrestricted online access } & \text { - Rigorous Peer Review Process } \\ & \text { - Authors Retain Copyrights } \\ \end{array}$

